\title{
Evaluation of diabetic peer support in Malawi
}

\author{
Henry T Mwakalinga ${ }^{1 *}$, Yamikani M Nuka ${ }^{2}$, Patrick C Banda ${ }^{2}$, Thuy D Bui ${ }^{3}$
}

\author{
1. Mzuzu Central Hospital \\ 2. Kamuzu Central Hospital \\ 3. University of Pittsburgh School of Medicine
}

Correspondace: *Henry T. Mwakalinga: (htmwakalinga@gmail.com)

\section{Background}

\section{Abstract}

Type 2 diabetes is a major health concern worldwide and requires urgent attention from health care providers and policy makers. Due to shortage of health care workers in low-income countries, peer support programs have been viewed as a viable option in management of diabetes and have shown to be effective in sub-Saharan Africa.

Objective

The aim of this study is to assess and evaluate the Kamuzu Central Hospital (KCH) diabetic peer support program's (DPSP) impact 4 years after its establishment by assessing knowledge, self-efficacy and behaviours of DPSP members compared to non-members.

Methodology

This is a cross-sectional study done among diabetic patients attending clinics between 12th August and 25th September 2018 at $\mathrm{KCH}$. Self and interviewer-administered questionnaires (designed based on validated survey instruments) were used. The participants $(\mathrm{n}=176)$ were recruited consecutively after consenting.

\section{Results}

Results showed DPSP members were more knowledgeable regarding the effects of skipping meals and sweet juice on blood glucose and conditions not associated with diabetes. In terms of self-efficacy and behaviour changes, DPSP members believe that they are more able to correct hypoglycaemia, to communicate their concerns to health workers and to perform daily foot exam compared to non-members.

\section{Conclusion}

The KCH (Lilongwe) Diabetes Peer Support program has positively impacted its members and should be scaled up to engage all diabetic patients in Malawi. Ongoing training for peer supporters is necessary to update and reinforce management, knowledge and skills, and to ensure fidelity in program implementation.

Key words: Evaluating, diabetes peer support program, Kamuzu Central Hospital, Malawi

\section{Introduction}

Type 2 diabetes is a major health concern worldwide and requires urgent attention from health care providers and policy makers. This problem is worse in low-income countries as there is double burden of infectious and noncommunicable disease such as diabetes ${ }^{1,2}$. It is estimated that by $2030,80 \%$ of people with diabetes mellitus will be living in low-income countries ${ }^{3}$. The prevalence of diabetes in Malawi is 5.6\% among adults aged between 25 and 64 years ${ }^{4}$. The high prevalence projection coupled with shortage of healthcare workers make self-management an even more critical component of diabetes prevention and treatment. The self-management of diabetes involves lifestyle modification such as improving diet, increasing physical activity, selfmonitoring of blood glucose levels, regular examination of feet and adherence to medication ${ }^{5}$.

Peer support programs that empower participants with lifestyle modification and treatment adherence have been shown to be helpful in sub-Saharan Africa ${ }^{6,7,8,9,10,11}$.

In Malawi, the traditional home-based care is one such example, which is less resource-intensive and has been shown to be a valuable component of the continuum of care and support for people living with HIV/AIDS. ${ }^{6}$ Additionally, peer group interventions have been shown to improve maternal and child health outcomes as well as HIV prevention in rural populations of $\mathrm{Malawi}^{7,8}$. A study done in Uganda by Baumann et al. indicated improvement in glycosylated hemoglobin (A1C), diastolic blood pressure, and eating behaviors with a conclusion that peer support program was a feasible intervention to improve diabetes care in rural Uganda?. Another study done in Mali by Debussche et al. of peer-led structured patient education delivered over 1year to patients with poorly controlled type 2 diabetes showed substantial improvement in glycemic control and anthropometric parameters ${ }^{10}$. Diabetes peer support interventions have been shown to improve patients' health behaviours, metabolic control, and quality of life in countries like Cameroon, South Africa and Uganda ${ }^{11}$.

In 2014, with funding from the World Diabetes Foundation, a diabetes peer support program (DPSP) was established at Kamuzu Central Hospital $(\mathrm{KCH})$ in Lilongwe, Malawi ${ }^{12}$. The goal of this program is to provide patients with diabetes selfmanagement skills that enable them to live healthy lives. The program focused on daily management assistance, promoting patient empowerment and community mobilization to strengthen linkages to existing healthcare infrastructure. The mobilization process was led by a volunteer nurse with experience in HIV home-based care and diabetes education to provide group diabetes education at the $\mathrm{KCH}$ diabetes clinic and to liaise with the Diabetes Association of Malawi. Topics covered in group education sessions include dietary planning, long-term complications of uncontrolled diabetes, foot care, medications adherence, recognition and self- 
management of hyper- and hypoglycaemia, self-monitoring of blood glucose and insulin injection techniques. The peer training curriculum utilized the extensive peer support training materials developed by the Peers for Progress organization (www.peersforprogress.org) and the curriculum for peer leaders developed by Tang and Funnell. The aim is for the peer supporters to act as advocates and coaches for group members through valuable skill training in problem solving, listening and facilitation.

By 2018, there were 30 groups with 1088 peer support members. Each group was provided with a glucometer and an automated BP machine. Peer support members meet once a month under the supervision of the lead peer supporters and trainers. The objective of this study is to assess and evaluate the program's impact 4 years after its establishment by assessing knowledge, self-efficacy and behaviours of DPSP members compared to non-members who attend the diabetic clinic at $\mathrm{KCH}$.

\section{Methodology \\ Study Design}

This is a cross-sectional descriptive study using selfand interviewer-administered questionnaires assessing knowledge, perception of self-efficacy and behaviours of participants.

\section{Study Setting and Population}

The study was done at Kamuzu Central Hospital among diabetic patients attending the outpatient diabetes/ hypertension clinic from 14th August 2018 to 25th September 2018. $\mathrm{KCH}$ is the main government referral hospital for the central region of the country. Patients were recruited while waiting to be seen by clinicians.

Criteria for survey participation included diagnosis of diabetes for at least one year or members of DPSP for one year or more.

\section{Sampling and Data Collection}

The questionnaire was designed based on validated survey instruments such as the Diabetes Knowledge Test (DKT), Diabetes Attitude Scale (DAS-3) and the Diabetes Empowerment Scale (DES), adapted for Malawi context ${ }^{13}$, 14,15 .

The actual questionnaire is available in the appendix ( in English and Chichewa). The survey questions were reviewed by the diabetes peer support trainer, lead supporters as well as clinicians at the diabetes clinic. We used convenient sampling where diabetic patients were recruited while waiting to see a clinician and verbal consent was obtained. Patients selfidentified whether they belonged to the diabetes peer support program or not. Patients who were not able to complete the paper survey on their own were given assistanceby clinic staff member. Basic sociodemographic information was collected without personal identifying data.

\section{Data Management and Analysis}

Descriptive statistics were computed to characterize participants using means and standard deviations for continuous variables and counts and percentages for categorical variables. The Chi-squared test was used for comparing categorical data between the two groups. Independent sample t-test was used to compare the mean age of members and non-members. P-values of less than 0.05 were considered as significant.

\section{Ethical Considerations and Privacy}

This study was approved by KCH Director as it was simply evaluating the effects of a project. We are presenting the results of this anonymous survey as a stand-alone study.

\section{Results}

There were 176 participants, and a summary of their demographic characteristics is shown in Table 1 . There were 98(55.68\%) DPSP members and 78(44.32\%) non-members. Mean age of members was 54 years compared to 48 years in non-members, and there were more women $60(61.22 \%)$ than men $38(38.78 \%)$ among peer support members. The majority of those on medications were on oral hypoglycaemics with more non-members on insulin. Table 2 shows a breakdown of the responses of the participants in terms of knowledge of diabetes and self-efficacy.

Table 1. Demographic characteristics of study population

\begin{tabular}{|l|l|l|l|}
\hline Variable & $\begin{array}{l}\text { DPSP Member } \\
(n=98)\end{array}$ & $\begin{array}{l}\text { Non Member } \\
(n=78)\end{array}$ & P value \\
\hline Age (Years) & $54.04 \pm 13.11$ & $47.73 \pm 13.87$ & \\
\hline $\begin{array}{l}\text { Gender } \\
\text { Male/Female }\end{array}$ & $38 / 60$ & $33 / 45$ & $0.0025^{*}$ \\
\hline $\begin{array}{l}\text { Level of Education } \\
\text { None }\end{array}$ & $26(26.50 \%)$ & $21(26.90 \%)$ & \\
Primary & $50(51.00 \%)$ & $41(52.60 \%)$ & 0.8325 \\
Secondary & $12(12.30 \%)$ & $11(14.10 \%)$ & \\
Tertiary & $10(10.20 \%)$ & $5(6.40 \%)$ & \\
\hline Medication & $1(1.02 \%)$ & $2(2.56 \%)$ & \\
Not on Medication & $79(80.61 \%)$ & $45(57.69 \%)$ & $0.0041^{*}$ \\
On Orals & $18(18.37 \%)$ & $31(39.74 \%)$ & \\
On Insulin & & & \\
\hline
\end{tabular}

\section{${ }^{*}$ p-value $<0.05$}

DPSP members were more knowledgeable on some aspects of the disease such as effects on blood sugar from sweet juice and skipping meals. They were also more knowledgeable on diabetic related complications. However, there was no significant difference between the 2 groups with regard to knowledge about the effect of infection on blood glucose levels. In terms of self-efficacy and behaviour changes, DPSP members believed in their ability to correct hypoglycaemia and to communicate their concerns to health workers.

Lastly, more DPSP members performed daily foot exam compared to non-members, reflecting the heavy emphasis on foot exam in the peer supporter training curriculum. There were no statistically significant differences in other aspects of self-efficacy and self-management such as food choices, weight control and coping with diabetes related stress. $46 \%$ of DPSP members reported exercising every day compared with $15 \%$ of non-members. However, $20 \%$ of DPSP members reported exercising 3 or 4 times per week compared with $32 \%$ of non-members. $30 \%$ of DPSP members and $40 \%$ of the non-members said they do not exercise at all. 
Table 2. Knowledge and self-efficacy of participants

\begin{tabular}{|c|c|c|c|}
\hline VARIABLE & DPSP MEMBER & NON-MEMBER & P-value \\
\hline \multicolumn{4}{|c|}{ 1) KNOWLEDGE } \\
\hline \multicolumn{4}{|c|}{ Knowledge of Effect of Sweet Juice on Blood Glucose* } \\
\hline \multirow[t]{2}{*}{ Poor } & $90(91.84 \%)$ & $45(57.69 \%)$ & $0.0000001^{*}$ \\
\hline & $8(8.16 \%)$ & $33(42.31 \%)$ & \\
\hline \multicolumn{4}{|c|}{ Knowledge of Effect of Skipping Meals After Taking Insulin* } \\
\hline Good & $51(52.04 \%)$ & $28(35.90 \%)$ & $0.0329^{*}$ \\
\hline Poor & $47(47.96 \%)$ & $50(64.10 \%)$ & \\
\hline \multicolumn{4}{|c|}{ Knowledge of Effect of Infection on Blood Glucose } \\
\hline Good & $59(60.20 \%)$ & $48(61.54 \%)$ & 0.8574 \\
\hline Poor & $39(39.80 \%)$ & $30(38.46 \%)$ & \\
\hline \multicolumn{4}{|c|}{ Knowledge of Conditions not Associated with DM * } \\
\hline Good & $48(48.98 \%)$ & $20(25.64 \%)$ & $0.0016^{*}$ \\
\hline Poor & $50(51.02 \%)$ & $58(74.36 \%)$ & \\
\hline
\end{tabular}

\begin{tabular}{|c|c|c|c|}
\hline 2) SELF-EFFIC & & & \\
\hline Choice of Food & & & \\
\hline Appropriate & $93(94.90 \%)$ & $74(94.87 \%)$ & 0.9938 \\
\hline Inappropriate & $5(5.10 \%)$ & $4(5.13 \%)$ & \\
\hline Adherence to $\mathrm{Me}$ & & & \\
\hline Good & $94(95.92 \%)$ & $73(93.59 \%)$ & 0.4859 \\
\hline Poor & $4(4.08 \%)$ & $5(6.41 \%)$ & \\
\hline Weight Control & & & \\
\hline Able & $86(87.75 \%)$ & $67(85.90 \%)$ & 0.7164 \\
\hline Unable & $12(12.25 \%)$ & $11(14.10 \%)$ & \\
\hline Ability to Test Gl & & & \\
\hline Able & $35(35.71 \%)$ & $28(35.90 \%)$ & 0.9799 \\
\hline Unable & $63(64.29 \%)$ & $50(64.10 \%)$ & \\
\hline Ability to Correct & & & \\
\hline Able & $93(94.90 \%)$ & $60(76.92 \%)$ & $0.0004^{*}$ \\
\hline Unable & $5(5.10 \%)$ & $18(23.08 \%)$ & \\
\hline Ability to Commu & & & \\
\hline Able & $98(100 \%)$ & $65(83.33 \%)$ & $0.00003^{*}$ \\
\hline Unable & $0(0 \%)$ & $13(16.67 \%)$ & \\
\hline Ability to Cope w & & & \\
\hline Able & $89(90.82 \%)$ & $63(80.77 \%)$ & 0.0544 \\
\hline Unable & $9(9.18 \%)$ & $15(19.23 \%)$ & \\
\hline
\end{tabular}




\begin{tabular}{|l|l|l|l|}
\hline 2) SELF-EFFICACY AND BEHAVIORS CONT... & & \\
\hline Ability to Identify Food High in Carbohydrates & & & \\
Able & & $47(60.26 \%)$ & 0.4905 \\
Unable & $64(65.31 \%)$ & $31(39.74 \%)$ & \\
& $34(34.69 \%)$ & & \\
\hline
\end{tabular}

This reflected a mixed picture on the tendency to exercise amongst the participants as well as different interpretation and perception of what was meant by exerciseor physical activity.

A majority of the participants $(69 \%)$ identified lack of money as the biggest obstacle to managing diabetes. This was followed by the cost of medication (61\%), availability of medications (52\%), lack of access to clinics (40\%), inability to eat right $(39 \%)$, lack of electricity $(19 \%)$, lack of time to exercise $(17 \%)$ and lack of running water. Even though medications are provided free of charge from government facilities, patients are forced to purchase their own when there are stock outs or when they are not able to come to clinic.

\section{Discussion}

This study evaluated the Lilongwe Diabetes Peer Support Program'simpacton members 4 yearsintoitsimplementation. DPSP members were generally better as compared to non DPSP members in terms of knowledge and self-efficacy on some aspects of diabetes care although data interpretation is limited by differences in demographic characteristics between the two groups. The most impressive findings are their confidence in communicating with healthcare providers and a higher proportion reporting daily foot examination. DPSP members were also more able to correct their hypoglycaemia $(94.90 \%)$ as compared to non-DPSP members $(76.92 \%)$. This could be attributed to the fact that DPSP members remind each other when they meet in their groups while the non-members have to wait for clinic days which come after 3 to 6 months for stable patients according to booking schedules. Furthermore, during clinic days, the non-DPSP members found it hard to communicate their concern to health workers as compared to DPSP members who have better health worker-patient relationship as a result of frequent interaction during community meetings. It is also possible that those who engaged in the peer support program were more motivated or had other personal attributes not captured in this study.

Ninety nine percent of our participants in both groups were taking medications regularly, similar to findings in a study done by Assayed et $\mathrm{al}^{16}$ on quality of care of diabetic patients in Mangochi District, rural Malawi. This can be attributed to government policy of providing free healthcare services which also extend to provision of free medications to diabetic patients, inclusion of NCDs like diabetes in the Essential Health Package ${ }^{17}$, and good adherence from patients. On the other hand, diabetic patients' ability to pursue lifestyle modifications were not really encouraging as seen in the pattern of the results above.

There was also higher female-to-male attendance ratio at the $\mathrm{KCH}$ clinic similar to that found in other districts in Malawi, a notable finding when compared to a nationwide assessment of NCD risk factors which revealed no significant differences in the prevalence of diabetes between males and females.
This would suggest that there are barriers that particularly affect men in accessing diabetes care.

The DPSP members were overall better in terms of knowledge but our results suggest that education to diabetic patients could be improved. In the Mangochi cohort ${ }^{16}$, more than half of patients had little or no information about diabetes. As for self-management skills, DPSP members were better in only three out of nine self-efficacy variables (ability to correct hypoglycaemia, ability to inform health worker, and daily feet examination). This suggests that peer support participation reinforced only some behaviours, similar to studies done by Baumann et $\mathrm{al}^{9}$, and Tang et $\mathrm{al}^{18}$. Baumann found that their peer group participants only did better in term of healthy eating behaviours, out of the multiple variables they were evaluating. The same was depicted in the study by Tang et al. where only diabetes distress score improved and HbA1c actually worsened among the peer group participants. The best results came from the study by Peimaniet $\mathrm{al}^{19}$ who found that peer support participants exhibited improvement in all the outcomes evaluated (HbA1c, mean diabetes selfmanagement scores, mean self-efficacy scores and mean quality of life scores) and hence portraying good effect of peer support services. The peer support component was more intense and focused on psychosocial support rather than just health education.

It is unclear why a higher percentage of non-members (40\%) were taking insulin compared to members (18\%)but the findings of a high percentage of non-members $(23.05 \%)$ having worse knowledge about skipping meals and unable to correct hypoglycaemia raise great concern as these might result in devastating consequences. This shows that patient education at the clinic is not enough and there is need for increased awareness and education. This lack of knowledge can be attributed to the fact that thorough patient education is only done when someone is newly diagnosed and at the beginning of each clinic session. Patients who come late due to the long distances they travel to access healthcare services might miss diabetic education. Due to the high volume and time constraint, patients needing individual attention don't get the needed teaching and counselling.

There were no significant differences between the two groups in terms of food choices, weight control and ability to identify food with high carbohydrate content. This can be due to the fact that most Malawians have limited food options due to food insecurity and poverty. According to Trade Economics, Malawi's GDP per capital was at 516.80 US dollars in 2018, equivalent to 4\% of the world's average ${ }^{20}$. When there is scarcity of food, many Malawian with diabetes will eat what's available rather than follow dietary guideline.

There was also no difference in the ability of participants to test and self-monitor blood glucose levels with only $35 \%$ from each group being able to test at home. This is similar to studies done in Nigeria which reported prevalence of selfmonitoring of blood glucose to range from $27 \%$ to $33 \% 0^{21,22}$.

This can be attributed to the fact that most patients cannot https://dx.doi.org/10.4314/mmj.v33i2.5 
afford a glucometer, test strips and needles. For members, access to home testing is also a challenge as 30 members in each support group have to share one glucometer and limited supply of test strips. Some members might also be anxious and fearful about pricking their fingers and were thus not interested and willing to learn about testing on their own. This is consistent with the study done by Brohi et al. which found that only $30.2 \%$ were able and adherent to self -monitoring of blood glucose. The majority reported that fear of needles and pain, cost of testing (strips and needles), and inconvenience as some of the barriers to self-monitoring of blood glucose $e^{23}$. Ugwuet al. also found that lack of finance and fear of needle prick were the predominant reasons for not performing self-monitoring blood glucose $\mathrm{e}^{24}$.

Despite the Malawian Government providing free medications, these medications are not always in stock and patients are asked to buy from private pharmacies. The biggest stressor for patients in this survey was the emotional and material cost to live with diabetes. Patients are worried about access to medications, transportation cost and travel time to clinic. This can be attributed to the low socioeconomic status and educational attainment of those in our survey.

One lesson from the study by Peimani et al. would be to invest more efforts in recruiting and training peer supporters to provide psychosocial support in addition to health education as this would be the best use of Malawi's human resources. Shortage of healthcare providers, medications and diagnostic testing will make diabetes care challenging in Malawi but management of chronic diseases even in the most resource-intense settings has taught us that behavioural change and quality of life are often the most difficult to achieve. Having a cadre of peer supporters well-qualified to provide social and emotional support to help patients deal with stress, link with community resources and clinical care would be a worthwhile and feasible goal.

\section{Limitations}

There are several limitations in this study. The biggest limitation is lack of baseline data. This study only captured a small proportion of patients attending the diabetes/ hypertension clinic at $\mathrm{KCH}$ and the survey was not validated for Malawian context. The participants' understanding and interpretation of the questions might be affected even when in-person interview was provided. We did not have access to $\mathrm{HbA1C}$ testing, BMI data and documentation of diabetic complications. Lastly, we did not survey the paediatric diabetic patients or their families.

\section{Conclusion \& Recommendation}

The Lilongwe Diabetes Peer Support program has positively impacted its members and should be scaled up to engage all diabetic patients in Malawi. Additional recruitment and ongoing training for peer supporters is necessary to reinforce and update management knowledge and skills, to provide psychosocial support and to ensure fidelity in program implementation. Peer support programs for chronic diseases have recently been developed in various regions in Malawi and a preliminary evaluation like this one suggests that it is a viable strategy for the NCD unit within the Ministry of Health.

\section{Acknowledgements}

We would like to thank Sister Olive Kadzakumanja (retired nurse and midwife), for her dedication in leading the Lilongwe Diabetic Peer Support Program and her help in recruiting the participants. We would also like to thank Drs. Jonathan Ngoma, Lillian Chunda, and Charles Munthali for their clinical leadership. We sincerely appreciate all participants who volunteered for this study. Finally, we would like to acknowledge Mr. Thomas Psyata(a journalist by profession) for assistance with translation of the questionnaire from English to Chichewa.

\section{Conflict of Interest}

Authors, Henry T Mwakalinga, Yamikani M Nuka, Patrick C Banda, and Thuy D Bui declare that they have no conflict of interest.

\section{References}

1. Agyei-MensahS, de-Graft Aikins A. Epidemiological transition and the double burden of disease in Accra, Ghana. J Urban Heal Bull New York Acad Med.2010;87:879-897. https://doi.org/10.1007/s11524-0109492-yPMID:20803094

2. Institute of Health Metrics. Global burden of disease: Profile Ghana [Internet]. Washington; 2010. Available: http://vizhub.healthdata.org/ gbd-compare/

3. International Diabetes Federation. IDF Diabetes Atlas, 5th ed. Brussels, Belgium: Author; 2012. (www.idf.org/diabetesatlas/5e).

4. Msyamboza KP, Ngwira B, Dzowela T, Mvula C, et al. The burden of selected chronic non-communicable diseases and their risk factors in Malawi: nationwide STEPS survey. Plos ONE 2011; 6(5): e20316.

5. Glasgow RE, Funnell MM, Bonomi AE, Davis C, Beckham V, Wagner EH. Self -management aspects of the improving chronic illness care breakthrough series: implementation with diabetes and heart failure teams. Ann Bahav Med. 2002;24(2);80-7.

6. Zachariah R, Teck R, Buhendwa L, Fitzerland M, Labana S, Chinji $\mathrm{C}$, et al. Community support is associated with better antiretroviral treatment outcomes in a resource-limited rural district in Malawi. Trans R Soc Trop Med Hyg 2007; 101:79-84.

7. Kaponda CP, Norr KF, Crittenden KS, Norr JL, et al. Outcomes of an HIV prevention peer group intervention for rural adults in Malawi. Health EducBehav 2011; 38(2):159-700.

8. Lewycka S, Mwansambo C, Rosato M, Kazembe P, et al. Effect of women's groups and volunteer peer counselling on rate of mortality, morbidity, and health behaviours in mothers and children in rural Malawi (MaiMwana): a factorial, cluster-randomised controlled trial. Lancet 2013; 381:1721-35

9. Baumann LC, Frederick N, BettyN,Jospehine E, Agatha N. A Demonstration of Peer Support for Ugandan Adults with Type 2 Diabetes. International Society of Behavioral Medicine; (2015) 22:374-383

10. Debussche X, BesancËon S, Balcou-Debussche M, Ferdynus C, Delisle H, Huiart L, et al. Structured peer-led diabetes self-management and support in a low-income country: The ST2EPrandomised controlled trial in Mali;(2018). PLoSONE13(1):e0191262.https://doi.org/10.1371/ journal.pone.0191262

11. Fisher EB, Boothroyd RI, Coufal MM, Baumann LC, et al. Peer support for self-management of diabetes improved outcomes in international settings. Health Affairs 2012; 31(1): 130-139.

12. Bui T D, Kadzakumanja O, Munthali C, Mobilizing for the Lilongwe Diabetes Peer Support Programme in Malawi: Malawi Medical Journal; 26 (4): 124-125 December 2014

13. Fitzgerald JT, Funnell MM, Anderson RM, Nwankwo R, Stansfield RB, Piatt GA. Validation of the Revised Brief Diabetes Knowledge Test (DKT). The diabetes Educator; 2016:42(2):178-187 
14. Anderson RM, Fitzgerald JT, Funnell MM, Grupen LD: The Third Version of The Diabetes Attitude Scale (DAS-3). Diabetes Care 21(9):1403-1407, 1998

15. Anderson RM, Fitzgerald JT, Funnell MM, Oh MS. The diabetes empowerment scale-short form (DES-SF). Diabetes Care 2003; 26:1641-1643

16. Assayed AA, Muula A S, Nyirenda MJ. The quality of care of diabetic patients in rural Malawi. A case of Mangochi district. Malawi Medical Journal 2014 Dec ; 26(4) : 109-114

17. Ministry of Health [Malawi]. Malawi Health Sector Strategic Plan 2011-2016 - moving towards equity and quality [Internet]. 2011. Available from: http://www.medcol.mw/commhealth/publications/3 Malawi HSSP Final Document (3).pdf TangTS,Sohal PS, Garg AK. Educational and Psychological Issues Rethinking Peer Support for Diabetes in Vancouver's South-Asian Community: A Feasibility Study: Diabet. Med 32, 1077-1084 (2015)

18. Peimani M, MonjazebiF,Ghodssi-Ghassemabadi R, Nasli-Esfahani E. A Peer Support Intervation In Imrpoving Glycaemic Control In Patients with Type 2 Diabetes: Elsevier B.V. 2017
19. World Bank (2020). Malawi GDP per capita PPP. Retrieved from Trading Economics: http://tradingeconomics.com/malawigdp percapita-ppp

20. Unachukwu CN, Young EE, Uchenna DI. Self-Blood Glucose Monitoring among Diabetic patients in Port-Harcourt, Nigeria. African Journal of Diabetes Medicine 2011; 19 (1): 19-20

21. Ambakederemo TE, Jumbo J, Dodiyi-Manuel ST. How much do diabetic patients know about self-monitoring of their blood sugar? PortHarcourt Medical Journal 2015; 9: 33-38.

22. Brohi AH, Hakim A, Khan M, et al. Facilitators and barriers of self-monitoring of blood glucose (SMBG) in diabetic patients visiting family medicine clinics at Akuh.

23. Ugwu ET, Orjioke CJG, Young EE. Self-Monitoring of Blood Glucose Among Patients with Type 2 Diabetes Mellitus in Eastern Nigeria: Need for Multi-strategic Interventions. Curr Diabetes Rev. 2018;14(2):175-181.doi:10.2174/153399812666161014111618. PMID: 27758706. 